\title{
A broad supersaturation scanning (BS2) approach for rapid measurement of aerosol particle hygroscopicity and cloud condensation nuclei activity
}

\author{
Hang Su${ }^{1}$, Yafang Cheng ${ }^{1}$, Nan $\mathrm{Ma}^{2}$, Zhibin Wang ${ }^{1}$, Xiaoxiang Wang ${ }^{1}$, Mira L. Pöhlker ${ }^{1}$, Björn Nillius ${ }^{1}$, \\ Alfred Wiedensohler ${ }^{2}$, and Ulrich Pöschl ${ }^{1}$ \\ ${ }^{1}$ Multiphase Chemistry Department, Max Planck Institute for Chemistry, 55020 Mainz, Germany \\ ${ }^{2}$ Leibniz-Institute for Tropospheric Research, 04318 Leipzig, Germany \\ Correspondence to: Yafang Cheng (yafang.cheng@mpic.de)
}

Received: 21 July 2015 - Published in Atmos. Meas. Tech. Discuss.: 17 September 2015

Revised: 23 August 2016 - Accepted: 1 September 2016 - Published: 24 October 2016

\begin{abstract}
The activation and hygroscopicity of cloud condensation nuclei $(\mathrm{CCN})$ are key to the understanding of aerosol-cloud interactions and their impact on climate. They can be measured by scanning the particle size and supersaturation in $\mathrm{CCN}$ measurements. The scanning of supersaturation is often time-consuming and limits the temporal resolution and performance of $\mathrm{CCN}$ measurements. Here we present a new approach, termed the broad supersaturation scanning (BS2) method, in which a range of supersaturation is simultaneously scanned, reducing the time interval between different supersaturation scans. The practical applicability of the BS2 approach is demonstrated with nano$\mathrm{CCN}$ measurements of laboratory-generated aerosol particles. Model simulations show that the BS2 approach may also be applicable for measuring $\mathrm{CCN}$ activation of ambient mixed particles. Due to its fast response and technical simplicity, the BS2 approach may be well suited for aircraft and long-term measurements. Since hygroscopicity is closely related to the fraction of organics/inorganics in aerosol particles, a BS2-CCN counter can also serve as a complementary sensor for fast detection/estimation of aerosol chemical compositions.
\end{abstract}

\section{Introduction}

Aerosol particles serving as cloud condensation nuclei $(\mathrm{CCN})$ influence the cloud formation process and play an important role in regulating the radiative budget of the earth system (Pruppacher and Klett, 1997). The abundance of $\mathrm{CCN}$ is one of the key prerequisites for better understanding and assessment of aerosol-cloud interactions and their effects on climate. To predict CCN concentrations, knowledge about the aerosol size distribution and $\mathrm{CCN}$ activities (hygroscopicity) is required.

The $\mathrm{CCN}$ activities can be determined by the size-resolved CCN measurements, in which both dry particle diameter $\left(D_{\mathrm{d}}\right)$ and supersaturation $(S)$ are scanned (Dusek et al., 2006; Frank et al., 2006; Moore and Nenes, 2009a; Snider et al., 2010; Kuwata et al., 2008; Gunthe et al., 2011; Rose et al., 2011; Petters et al., 2009; Wex et al., 2009; Wittbom et al., 2014). Based on such measurements, the CCN activity parameter (e.g., $\kappa$ ) can be determined by the corresponding Köhler equation (Köhler, 1936; Petters and Kreidenweis, 2007).

Fast scanning of $S$ is important for measurements of ambient $\mathrm{CCN}$ or laboratory-generated $\mathrm{CCN}$ with high temporal variability. The DMT (Droplet Measurement Technologies) $\mathrm{CCN}$ counter (CCNC) is one of the most commonly used CCNCs nowadays (Roberts and Nenes, 2005). The change of $S$ in this type of CCNC can be achieved by changing the thermal gradient in the activation tube. This approach requires a waiting time of a few minutes to stabilize the newly designated $S$, which largely reduces the time resolution of the $S$ scan. Due to the low time resolution, $\mathrm{CCN}$ activities are normally measured at only a few $S$ to account for the temporal variability of ambient aerosol particles (Gunthe et al., 2011; Rose et al., 2011). To increase the time resolution of the $S$ 
scan, Scanning Flow CCN Analysis (SFCA) was developed, in which $S$ was continuously adjusted by changing the flow rate in the activation tube (Moore and Nenes, 2009b). SFCA makes the rapid and continuous measurement of $S$ spectra possible, with a time resolution of $\sim 10-60 \mathrm{~s}$. Fast scanning of $S$ has also been achieved for other designs of CCNC in the work of Fukuta and Saxena (1979) and Hudson (1989).

This study presents a new approach, termed the broad supersaturation scanning (BS2) method, which measures the activation of size-resolved CCN simultaneously over a continuous range of $S$ and reduces the time required for the $S$ scan to the same time as required for a single diameter scan (in practice, the time resolution of the instrument is, e.g., $1 \mathrm{~s}$ for the DMT-CCNC). This enables a fast determination of $\kappa$, which is useful for both CCN modeling/prediction and estimation of aerosol chemical compositions (Wang et al., 2015). Besides advances in the time resolution, BS2-CCNC may be built with simple modifications of existing DMT-CCNC. In addition, both temperature gradient and flow rate are kept constant during the measurements, minimizing the potential problem of aerosol volatilization and technical complexity (Moore and Nenes, 2009b).

\section{Methodology}

\subsection{Concept of the BS2 approach}

For easy understanding, we introduce the BS2 method in comparison with previous designs and applications of the DMT-CCNC (note that the experimental evaluation in Sect. 3.3 was performed with a nano-CCNC instead of the DMT-CCNC). Figure 1a shows a typical distribution of supersaturation in the activation tube of DMT-CCNC, denoted by $S_{\text {tube }} . S_{\text {tube }}(r)$ is a function of $r$, the radial distance to the centerline of the activation unit. In Fig. 1, $S_{\text {tube }}(r)=$ $0.31 \times \cos (0.14 \times r)$, in which the unit of $S$ is $\%$ and the unit of $r$ is millimeters. The highest $S_{\text {tube }}(r)$ appears in the centerline $(r=0)$ and drops to 0 near the wall. Note that $S_{\text {tube }}$ in the activation tube also has an axial dependence (Roberts and Nenes, 2005); here we simply use $S_{\text {tube }}(r)$ to represent the maximum $S$ in the axial direction at a given $r$. A list of frequently used symbols is given in Appendix A.

Figure 1a and $\mathrm{b}$ show regular applications of DMT-CCNC, in which aerosol particles are focused on the centerline by a narrow aerosol inlet and laminar sheath flow. Such application ensures that aerosol particles are exposed to a single $S_{\text {tube }}(r=0)$ at the centerline (Fig. 1b). Then, depending on the values of $S_{\text {tube }}(r=0)$ and $S_{\text {aerosol }}$ (the critical activation supersaturation of aerosol particles), the activation fraction $F_{\text {act }}$ can be either $0\left(S_{\text {aerosol }}>S_{\text {tube }}(r=0)\right)$ or $1\left(S_{\text {aerosol }}<S_{\text {tube }}(r=0)\right)$.

Figure 1c shows the dependence of $F_{\text {act }}$ on $S_{\text {aerosol }}$ in a single $S$ scan (i.e., with a given $S_{\text {tube }}$ ). It is clear that the $F_{\text {act }}$ value ( 0 or 1$)$ measured in a single $S$ scan is not sufficient to determine $S_{\text {aerosol }}$ (because it corresponds to an infinite
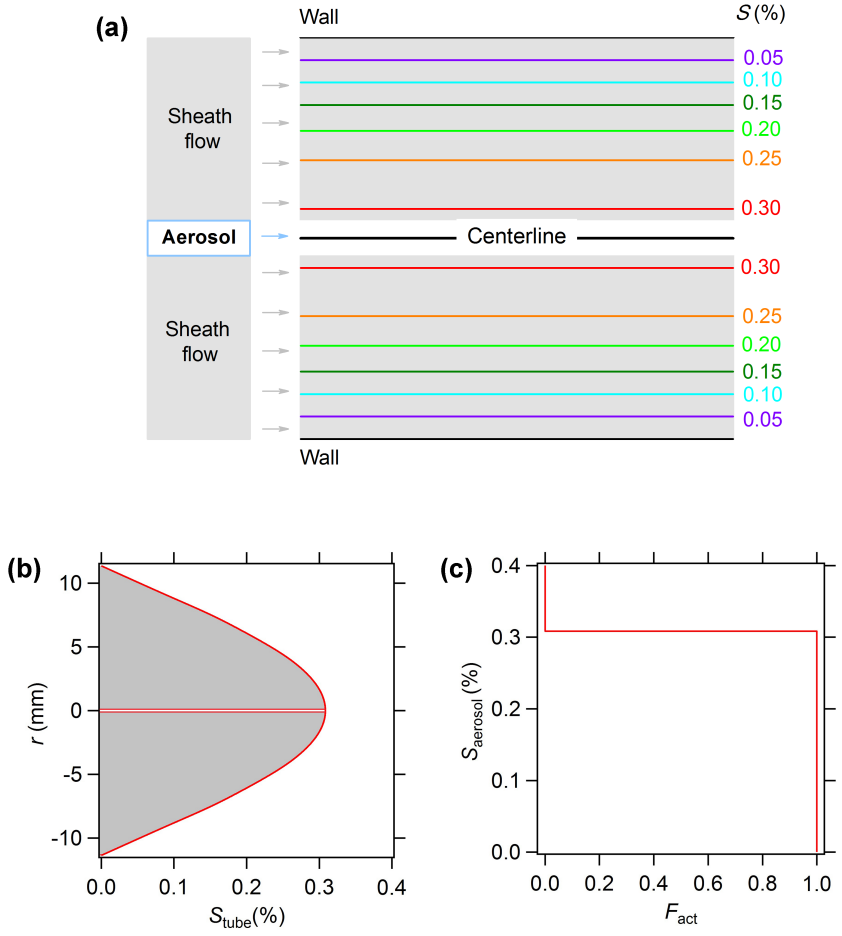

Figure 1. Schematics of typical CCN measurements. (a) Contour of supersaturation in the $\mathrm{CCN}$ activation unit and configuration of aerosol and sheath flow; (b) distribution of supersaturation in the activation unit $\left(S_{\text {tube }}\right) . r$ is the radial distance to the centerline. The shaded areas represent the sheath flow part, and the non-shaded areas represent the aerosol flow part. The $S_{\text {tube }}$ profile is adopted from http://nenes.eas.gatech.edu/Experiments/CFSTGC.html. (c) Plot of the activation supersaturation of aerosol particles $S_{\text {aerosol against }}$ the activation fraction $F_{\text {act }}$.

number of values of $S_{\text {aerosol }}$ ). To determine the exact $S_{\text {aerosol }}$, multiple $S$ scans (i.e., scanning different $S_{\text {tube }}$ ) are required until $F_{\text {act }}$ changes from 0 to 1 . The number of $S$ scans/steps in a spectrum determines the uncertainty of $S_{\text {aerosol }}$. When the adjustment of $S_{\text {tube }}$ is slow, only a few $S_{\text {tube }}$ can be scanned, leading to a large $S_{\text {tube }}$ interval and uncertainties in the derived $S_{\text {aerosol. }}$. That is why we need a fast $S$ scan approach such as BS2 or SFCA.

In the BS2 approach, we make use of the whole $S$ distribution inside the activation chamber. Instead of being focused at the centerline, the measured aerosol particles are introduced with a wider inlet of a high aerosol-to-sheath flow ratio and distributed in a broad cross section of the activation tube (Fig. 2). In this case, aerosol particles are exposed to a range of $S$ simultaneously. For a population of aerosol particles with the same $S_{\text {aerosol }}$, the total activation fraction, $F_{\text {act }}$, can be calculated by integrating the product of the flow velocity $v(r)$ and the activation fraction function $g(x)$ over the cross section of the aerosol flow, i.e., from the center $(r=0)$ 

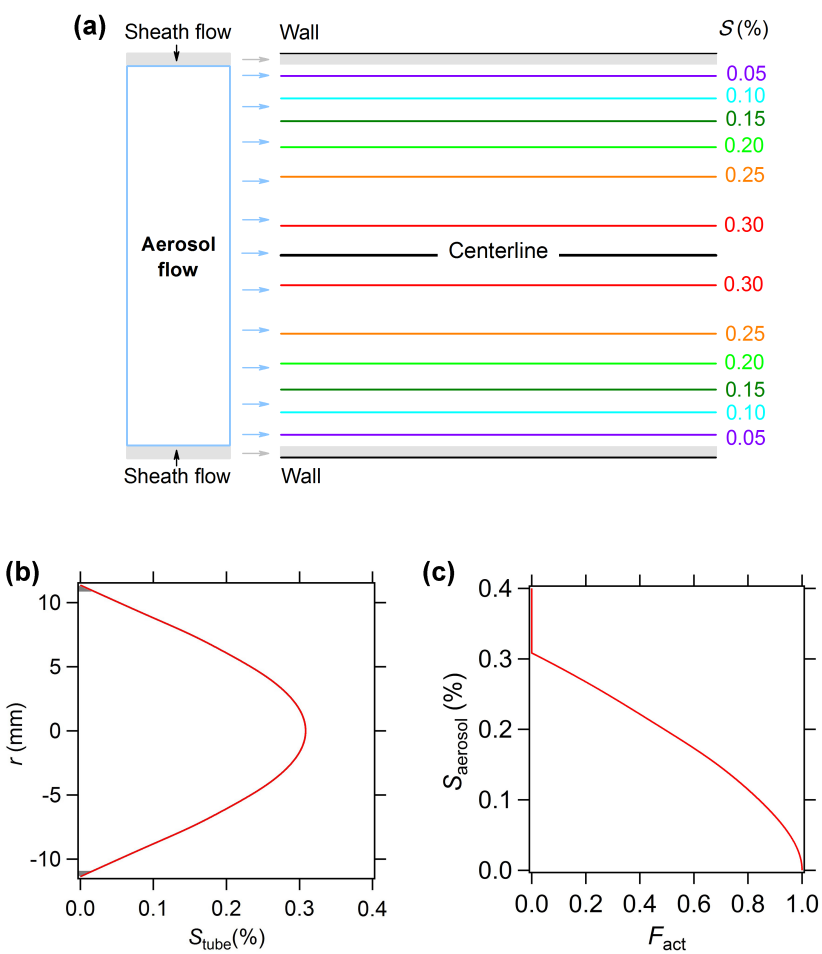

Figure 2. Schematics of BS2-CCN measurements. (a) Contour of supersaturation in the $\mathrm{CCN}$ activation unit and configuration of aerosol and sheath flow; (b) distribution of supersaturation in the activation unit $\left(S_{\text {tube }}\right) . r$ is the radial distance to the centerline. The shaded areas represent the sheath flow part, and the non-shaded areas represent the aerosol flow part. The $S_{\text {tube }}$ profile is adopted from http://nenes.eas.gatech.edu/Experiments/CFSTGC.html. (c) Plot of the activation supersaturation of aerosol particles $S_{\text {aerosol against }}$ the activation fraction $F_{\text {act }}$.

to the edge of the aerosol flow:

$$
\begin{aligned}
& F_{\text {act }}=\frac{2 \pi \int_{0}^{r} v g\left(S_{\text {aerosol }}-S_{\text {tube }}(r)\right) r \mathrm{~d} r}{2 \pi \int_{0}^{r} v r \mathrm{~d} r} \\
& g(x)= \begin{cases}1 & \text { if } x \leq 0 \\
0 & \text { if } x>0\end{cases}
\end{aligned}
$$

Figure 2c shows the dependence of $F_{\text {act }}$ on $S_{\text {aerosol }}$ for a BS2 measurement based on the $S_{\text {tube }}$ distribution in Fig. $2 \mathrm{~b}$ and a prescribed flow velocity profile of $v(r)=v_{\mathrm{m}} \times\left(1-r^{2} / R^{2}\right)$, where $v_{\mathrm{m}}$ is the maximum velocity at the centerline of the activation unit. Such monotonic dependence suggests that $S_{\text {aerosol }}$ can be directly determined once $F_{\text {act }}$ is measured. For a given $S_{\text {tube }}(r=0)$ profile, we have a fixed $F_{\text {act }}-S_{\text {aerosol }}$ relation (Fig. 2c), which can be determined with calibration aerosols (Sect. 2.2). The upper limit of measurable $S_{\text {aerosol }}$ by BS2 equals the maximum $S_{\text {tube }}$ on the centerline, while ideally, the lower limit can be zero depending on the width of the aerosol flow in relevance to the activation tube (Fig. 2a). For size-resolved measurements, we can calculate the effective hygroscopicity parameter $\kappa$ of aerosols particles from
$S_{\text {aerosol }}$ and the particle diameter $D_{\mathrm{d}}$ by solving the $\kappa$-Köhler equation (Petters and Kreidenweis, 2007; Su et al., 2010). Equation (2) gives an approximate solution for the effective $\kappa:$

$$
\kappa \approx \frac{4 A^{3}}{27\left(\ln \left(S_{\text {aerosol }} / 100 \%+1\right)\right)^{2} D_{\mathrm{d}}^{3}} \text { with } A=\frac{4 \sigma_{\mathrm{sol}} M_{\mathrm{w}}}{R T \rho_{\mathrm{w}}},
$$

where $\sigma_{\mathrm{sol}}$ is the surface tension of water, $M_{\mathrm{w}}$ is the molar mass of water, $R$ is the gas constant, $T$ is the temperature in Kelvin and $\rho_{\mathrm{w}}$ is the density of liquid water. Note that Eq. (2) provides only an approximation, of which the accuracy deteriorates as $\kappa$ and $D_{\mathrm{d}}$ decreases (Fig. S1 in the Supplement). We thus recommend using the numerical iteration method for a more accurate solution of $\kappa$, e.g., as in the work of Rose et al. (2008).

\subsection{Calibration}

For the BS2 calibration, the goal is to determine the monotonic $F_{\text {act }}-S_{\text {aerosol }}$ relation as shown in Fig. 2c. This can be achieved by performing size-resolved measurements of pure calibration aerosols with known hygroscopic properties, e.g., ammonium sulfate aerosol particles. Each $D_{\mathrm{d}}$ corresponds to a specific $S_{\text {aerosol }}$, and Eq. (3) gives an approximate solution. By recording the corresponding $F_{\text {act }}$, we get the calibration curve of the $F_{\text {act }}-S_{\text {aerosol }}$ relation.

$S_{\text {aerosol }} \approx 100 \% \times\left(\exp \left(\sqrt{\frac{4 A^{3}}{27 \kappa D_{\mathrm{d}}^{3}}}\right)-1\right)$

\subsection{Application}

The first step for the BS2 measurement is to select proper $S_{\max }$, the maximum $S_{\text {tube }}$ in the centerline of the activation unit. $S_{\max }$ should be higher than the highest $S_{\text {aerosol }}$ of investigated aerosol particles. Given the range of particle size and $\kappa, S_{\max }$ can be estimated by solving the $\kappa$-Köhler equation. An example is given in Fig. S2 to illustrate the relationship between $S, \kappa$ and $D_{\mathrm{d}}$. The adjustment of $S_{\max }$ can be done by changing the temperature gradient of the tube (Roberts and Nenes, 2005; Rose et al., 2008; Wang et al., 2015).

Once a proper temperature gradient is selected, we can perform size-resolved CCN measurements with BS2 analysis and record the BS2 activation spectra, i.e. the activation fraction $F_{\text {act }}$ as a function of the dry particle diameter $D_{\mathrm{d}}$. Based on the calibration curve (i.e., $F_{\text {act }}-S_{\text {aerosol }}$ relation), we can calculate the size-resolved $S_{\text {aerosol }}$ as well as $\kappa$. Figure 3 shows the modeled size-resolved $F_{\text {act }}-\kappa$ relation for a $S_{\text {tube }}(r)$ profile as given in Fig. $2 \mathrm{~b}$.

To demonstrate the concept of BS2 approach, a nano-CCN counter (Wang et al., 2015) was employed to perform sizeresolved measurements of laboratory-generated aerosol particles. The nano-CCN counter was developed to measure aerosol activation activity in the size range of 2 to $10 \mathrm{~nm}$. In this size range, aerosol particles are of high diffusivity and 


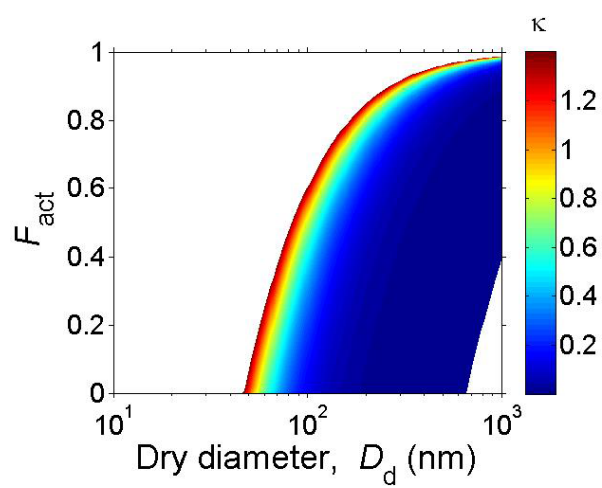

Figure 3. The activation fraction $F_{\text {act }}$ measured by a BS2-CCNC as a function of particle dry diameter $D_{\mathrm{d}}$ and $\kappa$. The $S_{\text {tube }}$ profile of the BS2-CCNC is taken the same as in Fig. 2b.

go beyond the initial flow constraint. Thus, aerosol particles are widely distributed in the activation unit of a nano-CCNC, and BS2 analysis can be directly applied without modification of the system.

\subsection{Correction for multiply charged particles}

When the differential mobility analyzer (DMA) selects particles of a given electrical mobility, the particles are not all singly charged. There are also multiply charged particles that have the same electrical mobility but are larger in diameter. The influence of the multiple charges can be corrected by subtracting the contribution of multiply charged particles from the measured number concentrations of total aerosol particles (condensation nuclei, $\mathrm{CN}$ ) and $\mathrm{CCN}$. The correction for the multiply charged $\mathrm{CN}$ and $\mathrm{CCN}$ can be done with a standard inversion algorithm for the size distribution correction (Hoppel, 1978). The correction procedure for a size-resolved BS2-CCNC measurement is the same as for a size-resolved DMT-CCNC measurement. Figure S3 shows an example of corrected and uncorrected $F_{\text {act }}$ for laboratorygenerated ammonium sulfate aerosol particles.

\section{Results and discussion}

\subsection{Imperfect internally mixed aerosol with a single $\kappa$ mode}

For aerosol particles of the same composition (pure compounds or perfectly internally mixed compounds), their $S_{\text {aerosol }}$ and $\kappa$ values can be readily determined as described in Sect. 2.3. Under ambient conditions, however, aerosol particles (even of the same size) often consist of different chemical compositions and hence different $\kappa$ (Lance et al., 2007; Su et al., 2010; Gunthe et al., 2011). In this section and Sect. 3.2, we will discuss the application of the BS2 approach to the ambient measurements.

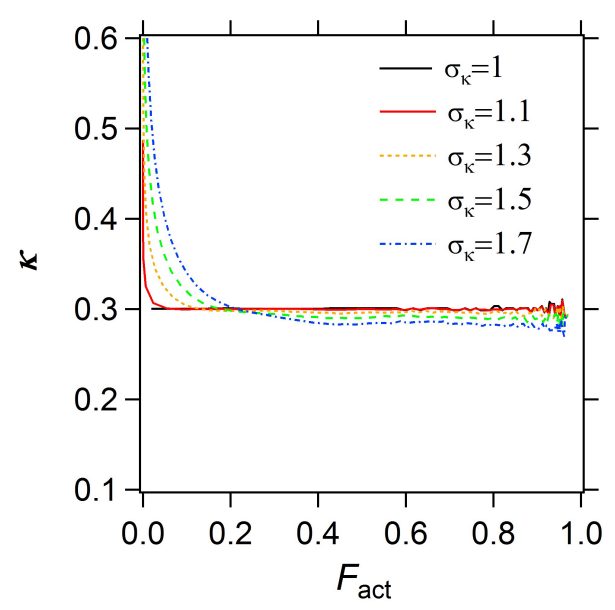

Figure 4. Influence of aerosol hygroscopicity $(\kappa)$ distribution on the retrieval of $\kappa$ by BS2-CCNC. $\sigma_{\kappa}$ represents the geometric standard deviation of the aerosol hygroscopicity $(\kappa)$ distribution.

Most CCN and HTDMA (hygroscopic tandem differential mobility analyzer) measurements show that ambient aerosol particles often have a near-single log-normally distributed $\kappa$ mode, especially at the clean and background sites (Su et al., 2010). Here we assume that the investigated aerosol particles have a $\log$-normal $\kappa$ distribution with a geometric mean $\kappa$ of 0.3 . Since the broadening of $\kappa$ distribution is a major difference between pure and ambient aerosol particles, we take a series of broadening factors, i.e. the geometric standard deviations $\sigma_{\kappa}$ of the $\kappa$ distribution, for further discussion of the BS2 application.

As shown in Fig. 4, for aerosols with a single $\kappa$ value $\left(\sigma_{\kappa}=1\right)$, we can get the same $\kappa$ value of 0.3 . For aerosols with a broad $\kappa$ distribution, the retrieved $\kappa$ depends on $F_{\text {act }}$. When $F_{\text {act }}>0.2$, the retrieved $\kappa$ is very close to their geometric mean value, with a relative difference of $<5 \%$. When $F_{\text {act }}<0.2$, the retrieved $\kappa$ can be largely biased from the geometric mean. The reason for this is as follows. Since $F_{\text {act }}$ shows a monotonic dependence on $\kappa$, a $\kappa$ distribution will in fact result in a $F_{\text {act }}$ distribution. Then, the influence of high and low $F_{\text {act }}$ will largely cancel out, leading to a $\kappa$ close to the geometric mean value. When $F_{\text {act }}$ is close to zero, the influence becomes asymmetric (because $F_{\text {act }}$ of the less hygroscopic aerosols cannot be smaller than zero). Then, the effect of more hygroscopic aerosols dominates the signal, resulting in a much higher retrieved $\kappa$. In such a case, we may increase the $S_{\max }$ to ensure $F_{\text {act }}>0.2$.

Besides $\kappa$, the CCN activity of aerosol particles also depends on their size. As limited by the transfer function of the DMA, a monodisperse aerosol selected by a DMA consists not only of particles with the selected nominal mobility equivalent diameter, but also contains smaller and larger particles. The nonuniform size can lead to similar effects as the nonuniform $\kappa$. According to Eq. (2), we can estimate the distribution of $D_{\mathrm{d}}$, which shows equivalent effects 
on $S_{\text {aerosol }}$ and measured $F_{\text {act }}$ as a given $\kappa$ distribution, i.e., $\Delta \ln D_{\mathrm{d}} \approx-\frac{1}{3} \Delta \ln \kappa$. Based on the relation between the mobility width and the aerosol-to-sheath flow ratio, and taking $3 \ln D_{\mathrm{d}}$ as an approximation of the half width of mobility diameter, we determine an equivalent DMA aerosol-to-sheath flow ratio of 1.05 for a $\sigma_{k}$ of 1.7 (Fig. 4). Thus, for a typical aerosol-to-sheath flow ratio of $1: 10(\ll 1.05)$, we will expect a minor influence of DMA transfer function on the retrieved $\kappa$. Note that the aerosol-to-sheath ratio here is for the DMA and is different from that in the $\mathrm{CCN}$ counter.

\subsection{Externally mixed aerosols with two $\kappa$ modes}

At clean and background sites, most CCN and HTDMA measurements show a single $\kappa$ mode. During biomass burning events, another less hygroscopic mode often appears at size range of $D_{\mathrm{d}}>100 \mathrm{~nm}$ (Rose et al., 2011). In Fig. 5a, we assume that aerosols have two log-normally distributed $\kappa$ modes with the same $\sigma_{\kappa}$ (geometric standard deviation of $\kappa)$ of 1.5, but different mode $\kappa$ of 0.3 and 0.01 (Rose et al., 2011). Then, the $\kappa$ distribution can be described by the probability density function $h(\kappa)$ as

$$
\begin{aligned}
h(\kappa) & =\frac{a_{\kappa} 0.01}{\sqrt{2 \pi} \log \sigma_{\kappa}} \exp \left(-\frac{(\log \kappa-\log 0.01)^{2}}{2\left(\log \sigma_{\kappa}\right)^{2}}\right) \\
& +\frac{a_{\kappa} 0.3}{\sqrt{2 \pi} \log \sigma_{\kappa}} \exp \left(-\frac{(\log \kappa-\log 0.3)^{2}}{2\left(\log \sigma_{\kappa}\right)^{2}}\right),
\end{aligned}
$$

where $a_{\kappa} 0.3$ and $a_{\kappa} 0.01$ represent the number fractions of the two modes, which are size-dependent in the 100-200 nm size range (Rose et al., 2011), as follows:

$a_{\kappa} 0.01=0.3 \times \log _{10}\left(D_{\mathrm{d}} / 30\right)$ and $a_{\kappa} 0.01=1-a_{\kappa} 0.3$,

where the unit of $D_{\mathrm{d}}$ is nanometers.

Figure $5 \mathrm{~b}$ shows the modeled result for measurements with a BS2 approach (labeled as "apparent"). The retrieved $\kappa$ varies from 0.11 to 0.26 , which lies between the $\kappa$ values of the two modes (i.e., 0.01 and 0.3 ). This is because the measured activation fraction $F_{\text {act }}$ is an average of individual modes weighted by their number fraction:

$$
\begin{aligned}
F_{\text {act }} & =a_{\kappa} 0.3 \times F_{\text {act }, \kappa 0.3}+a_{\kappa} 0.01 \times F_{\text {act }, \kappa 0.01} \\
& =\left(1-a_{\kappa} 0.01\right) \times F_{\text {act }, \kappa 0.3}+a_{\kappa} 0.01 \times F_{\text {act }, \kappa 0.01} .
\end{aligned}
$$

The retrieved $\kappa(\sim 0.11$ to 0.26$)$ follows the change of the geometric mean values ( $\sim 0.11$ to 0.18$)$ and represents certain kinds of weighted average of the two $\kappa$ modes. This result suggests that the BS2-CCNC alone cannot be used to resolve the multimode structure of $\kappa$ distribution.

To resolve the dual $\kappa$ mode or multiple $\kappa$ mode, we need to decouple the mixed information in Eq. (6) and extract the signal of each mode (i.e., $F_{\text {act }}, \kappa 0.3$ or $F_{\text {act }}, \kappa 0.01$ ) by combining BS2-CCNC with other complimentary techniques. The idea here is (1) to use the DMT-CCNC to determine $a_{\kappa} 0.01$, and
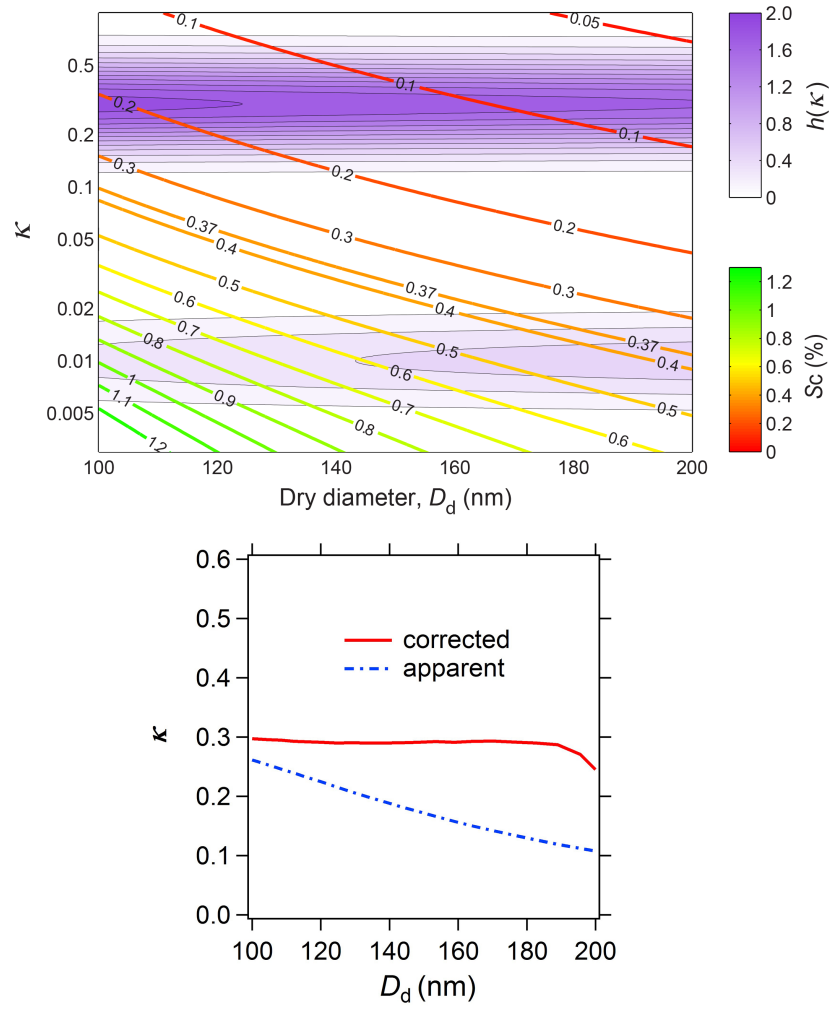

Figure 5. (a) Supersaturation required to activate the less hygroscopic mode by the DMT-CCNC. The shaded isolines show the normalized size-resolved hygroscopicity distribution $h(\kappa)$, the probability density function of a two-mode $\kappa$ distribution (Rose et al., 2011). The colored isolines represent the supersaturation required to activate particles for a certain dry diameter $D_{\mathrm{d}}$ and $\kappa$. (b) Model simulations of $\kappa$ retrieved for the more hygroscopic mode by BS2CCNC with (labeled as "corrected") and without (labeled as "apparent") complementary measurements of the DMT-CCNC.

(2) to choose a $S_{\max }$ of BS2-CCNC low enough so that $F_{\text {act }}$, $\kappa 0.01=0$. In such a way, we can solve $F_{\text {act, } \kappa} 0.3$ from Eq. (6) and determine $\kappa$ of the more hygroscopic mode. In the 100 to $200 \mathrm{~nm}$ size range, for example, the two aforementioned hygroscopic modes can be separated by setting $S$ of DMTCCNC to be around $0.37 \%$ (Fig. 5a), and setting $S_{\max }$ and $S_{\text {tube }}$ profiles of BS2-CCNC to be the same as in Fig. $2 \mathrm{~b}$.

Figure $5 \mathrm{~b}$ shows that we are able to resolve the mean $\kappa$ of the more hygroscopic mode (labeled as "corrected") with such a combination of measurements. $\kappa$ of the less hygroscopic mode can be resolved with a similar approach, in which we run the DMT-CCNC in parallel, with an $S$ of $0.37 \%$ and a BS2-CCNC with higher $S_{\max }(\sim 1.5 \%)$ and $S_{\min }$ of $\sim 0.37 \%$. The adjustment of $S_{\min }$ can be done by changing the width of the aerosol flow with new designs of inlets.

Figure $5 \mathrm{~b}$ also shows a relatively large deviation of retrieved $\kappa$ when $D_{\mathrm{d}}$ approaches $200 \mathrm{~nm}$. This is due to the imperfect separation of the two hygroscopic modes by the 


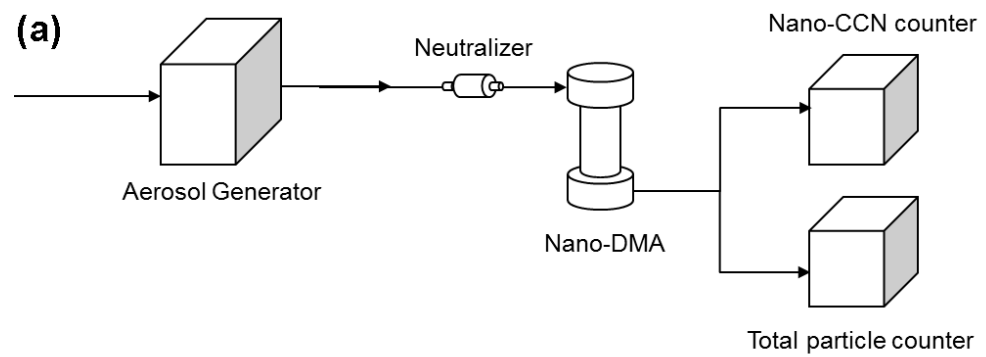

(b)

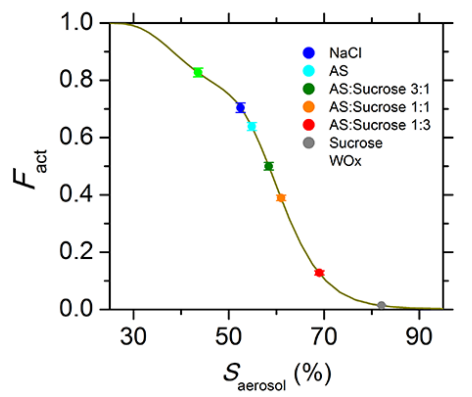

(c)

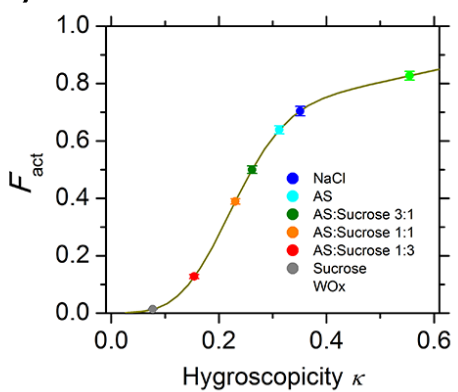

Figure 6. (a) Schematic of the setup for nano-CCNC measurements; (b) dependence of activation fraction $F_{\text {act }}$ on the aerosol activation

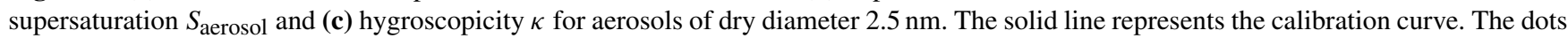
represent measurement results of different compounds in which AS denotes ammonium sulfate and WOx denotes tungsten oxides. The error bars represent the uncertainties of $F_{\text {act }}$.

DMT-CCNC. As shown in Fig. 5a, the activation $S$ drops as $D_{\mathrm{d}}$ increases. For $D_{\mathrm{d}} \sim 200 \mathrm{~nm}$, an $S$ of $0.37 \%$ becomes so high that even aerosol particles in the less hygroscopic mode will be activated. This leads to an overestimate of activation fraction of the more hygroscopic mode and an underestimation of the corresponding $\kappa$.

The size dependence of $S$ suggests that a single $S$ from DMT-CCNC will serve the separation purpose for a limited size range. To maintain the separation function, we need to adjust $S$ according to the value of $D_{\mathrm{d}}$. Figure $\mathrm{S} 4$ shows sizedependent $S$ for $\kappa$ of 0.05 . In practice, such scanning can be achieved by using Scanning Flow CCN Analysis (SFCA) for DMT-CCNC.

\subsection{Evaluation of the BS2 approach}

Figure 6a shows the experimental setup for evaluating the BS2 analysis. The setup is similar to normal size-resolved $\mathrm{CCN}$ measurements except that a nano- $\mathrm{CCN}$ counter (Wang et al., 2015) is used instead of a DMT-CCN counter. The nano-CCN counter was developed for measuring aerosol activation in the size range of 2 to $10 \mathrm{~nm}$. In this size range, aerosol particles are of high diffusivity and go beyond the initial flow constraint. Thus, aerosol particles are widely distributed in the activation unit of a nano-CCNC and BS2 analysis can be directly applied without modification of the system.
Figure $6 \mathrm{~b}$ and c show the $F_{\text {act }}-S_{\text {aerosol }}$ relation and $F_{\text {act }}-\kappa$ relation determined from a size-resolved nano-CCNC measurement. The solid line represents the calibration curve (using tungsten oxides particles as calibration aerosol; Wang et al. 2015). It confirms the monotonic dependence of $F_{\text {act }}$ on $S_{\text {aerosol }}$. Then, by measuring $F_{\text {act }}$ of monodisperse aerosols, we can determine $S_{\text {aerosol }}$ as well as $\kappa$ (Eq. 2). As shown in Fig. 6, a larger $F_{\text {act }}$ corresponds to a smaller $S_{\text {aerosol }}$ and a higher $\kappa$ (more hygroscopic). Note that $\kappa$ in this size range is different from previous $\mathrm{CCN}$ measurements due to the concentration and size dependence of $\kappa$ and relevant thermodynamic parameters (Wang et al., 2015; Cheng et al., 2015).

\section{Conclusions}

As a new concept for the design of $\mathrm{CCN}$ counters, the broad supersaturation scanning (BS2) approach reduces the time required for scanning supersaturation and can produce $\kappa$ of high temporal and size resolution. The principle of BS2 analysis has been demonstrated by laboratory experiments with a nano-CCNC. Model simulations show that the BS2 analysis is applicable for mixed particles with a single $\kappa$ mode. It may also be applied to aerosol particles with multiple $\kappa$ modes when complementary measurements are performed in parallel.

The BS2 approach requires relatively simple modification of existing thermal gradient CCN counters (such as DMT$\mathrm{CCNC}$ ). The data process procedure of $\mathrm{BS} 2$ analysis is even 
easier than for the present size-resolved CCN measurements. In addition, both temperature gradient and flow rate are kept constant during the measurements, minimizing the technical complexity and system stability. The fast response and stability of BS2 analysis may be well suited for aircraft and long-term measurements. Because $\kappa$ is closely related to the fraction of organics/inorganics in aerosol particles, BS2 can also serve as a complementary sensor for fast detection/estimation of aerosol chemical compositions.

\section{Data availability}

All the data presented in this study are available from the authors upon request (h.su@mpic.de or yafang.cheng@mpic.de). 
Appendix A: Notation (frequently used symbols and acronyms)

\begin{tabular}{|c|c|c|}
\hline Symbol & Unit & Quantity \\
\hline BS2 & & Broad supersaturation scanning \\
\hline $\mathrm{CCN}$ & & Cloud condensation nuclei \\
\hline $\mathrm{CCNC}$ & & Cloud condensation nuclei counter \\
\hline $\mathrm{CN}$ & & Condensation nuclei \\
\hline$D_{\mathrm{d}}$ & $\mathrm{m}$ & Dry particle diameter \\
\hline$F_{\text {act }}$ & & $\begin{array}{l}\text { Number fraction of activated aerosol } \\
\text { particles in the CCN counter }\end{array}$ \\
\hline HTDMA & & $\begin{array}{l}\text { Hygroscopic tandem differential } \\
\text { mobility analyzer }\end{array}$ \\
\hline$h(\kappa)$ & & Hygroscopicity $(\kappa)$ distribution function \\
\hline$M_{\mathrm{w}}$ & $\mathrm{kg} \mathrm{mol}^{-1}$ & Molar mass of water \\
\hline$R$ & $\mathrm{JK}^{-1} \mathrm{~mol}^{-1}$ & Universal gas constant \\
\hline$r$ & $\mathrm{~mm}$ & $\begin{array}{l}\text { Radial distance to the centerline of the } \\
\text { activation unit }\end{array}$ \\
\hline$S$ & $\%$ & Water vapor supersaturation \\
\hline$S_{\text {aerosol }}$ & $\%$ & $\begin{array}{l}\text { Critical activation supersaturation of } \\
\text { aerosol particles }\end{array}$ \\
\hline$S_{\max }$ & $\%$ & $\begin{array}{l}\text { Maximum water vapor supersaturation at } \\
\text { the centerline of a CCN counter }\end{array}$ \\
\hline$S_{\min }$ & $\%$ & $\begin{array}{l}\text { Maximum water vapor supersaturation at } \\
\text { the edge of the aerosol flow in the } \\
\text { activation unit }\end{array}$ \\
\hline$S_{\text {tube }}$ & $\%$ & $\begin{array}{l}\text { Maximum water vapor supersaturation in } \\
\text { the axial direction for a given } r\end{array}$ \\
\hline$T$ & $\mathrm{~K}$ & Temperature \\
\hline$v(r)$ & $\mathrm{m} \mathrm{s}^{-1}$ & Flow velocity in the $\mathrm{CCN}$ activation unit \\
\hline$v_{\mathrm{m}}$ & $\mathrm{m} \mathrm{s}^{-1}$ & $\begin{array}{l}\text { Maximum velocity at the centerline of the } \\
\text { CCN activation unit }\end{array}$ \\
\hline WOx & & Tungsten oxides \\
\hline$\kappa$ & & Effective hygroscopicity parameter \\
\hline$\sigma_{\kappa}$ & & $\begin{array}{l}\text { Geometric standard deviation in a } \\
\text { log-normal } \kappa \text { distribution }\end{array}$ \\
\hline$\sigma_{\mathrm{sol}}$ & $\mathrm{J} \mathrm{m}^{-2}$ & Surface tension of water \\
\hline$\rho_{\mathrm{w}}$ & $\mathrm{kg} \mathrm{m}^{-3}$ & Density of pure water \\
\hline
\end{tabular}




\section{The Supplement related to this article is available online at doi:10.5194/amt-9-5183-2016-supplement.}

Acknowledgements. This study was supported by the Max Planck Society (MPG), National Science Foundation of China (NSFC, grant no. 41330635), the Minerva Programme and EU FP7 project BACCHUS (project no. 603445). We would like to thank Cerina Wittbom and an anonymous referee for their constructive comments and suggestions.

The article processing charges for this open-access publication were covered by the Max Planck Society.

Edited by: P. Laj

Reviewed by: C. Wittbom and one anonymous referee

\section{References}

Cheng, Y., Su, H., Koop, T., Mikhailov, E., and Pöschl, U.: Size dependence of phase transitions in aerosol nanoparticles, Nat. Commun., 6, 5923, doi:10.1038/ncomms6923, 2015.

Dusek, U., Frank, G. P., Hildebrandt, L., Curtius, J., Schneider, J., Walter, S., Chand, D., Drewnick, F., Hings, S., Jung, D., Borrmann, S., and Andreae, M. O.: Size Matters More Than Chemistry for Cloud-Nucleating Ability of Aerosol Particles, Science, 312, 1375-1378, doi:10.1126/science.1125261, 2006.

Frank, G. P., Dusek, U., and Andreae, M. O.: Technical note: A method for measuring size-resolved $\mathrm{CCN}$ in the atmosphere, Atmos. Chem. Phys. Discuss., 6, 4879-4895, doi:10.5194/acpd-64879-2006, 2006.

Fukuta, N. and Saxena, V. K.: A Horizontal Thermal Gradient Cloud Condensation Nucleus Spectrometer, J. Appl. Meteorol., 18, 1352-1362, 1979.

Gunthe, S. S., Rose, D., Su, H., Garland, R. M., Achtert, P., Nowak, A., Wiedensohler, A., Kuwata, M., Takegawa, N., Kondo, Y., Hu, M., Shao, M., Zhu, T., Andreae, M. O., and Pöschl, U.: Cloud condensation nuclei $(\mathrm{CCN})$ from fresh and aged air pollution in the megacity region of Beijing, Atmos. Chem. Phys., 11, 1102311039, doi:10.5194/acp-11-11023-2011, 2011.

Hoppel, W. A.: Determination of the aerosol size distribution from the mobility distribution of the charged fraction of aerosols, J. Aerosol Sci., 9, 41-54, doi:10.1016/0021-8502(78)90062-9, 1978.

Hudson, J. G.: An Instantaneous CCN Spectrometer, J. Atmos. Ocean. Tech., 6, 1055-1065, 1989.

Köhler, H.: The nucleus in the growth of hygroscopic droplets, T. Faraday Soc., 32, 1152-1161, 1936.

Kuwata, M., Kondo, Y., Miyazaki, Y., Komazaki, Y., Kim, J. H., Yum, S. S., Tanimoto, H., and Matsueda, H.: Cloud condensation nuclei activity at Jeju Island, Korea in spring 2005, Atmos. Chem. Phys., 8, 2933-2948, doi:10.5194/acp-8-2933-2008, 2008.

Lance, S.: Quantifying compositional impacts of ambient aerosol on cloud droplet formation, $\mathrm{PhD}$ thesis, Georgia Institute of Technology, Atlanta, GA, USA, 2007.
Moore, R. H. and Nenes, A.: Scanning Flow CCN Analysis: Method for Fast Measurements of CCN Spectra, Aerosol Sci. Tech., 43, 1192-1207, 2009a.

Moore, R. H. and Nenes, A.: Scanning Flow CCN Analysis - A Method for Fast Measurements of CCN Spectra, Aerosol Sci. Tech., 43, 1192-1207, doi:10.1080/02786820903289780, 2009b.

Petters, M. D. and Kreidenweis, S. M.: A single parameter representation of hygroscopic growth and cloud condensation nucleus activity, Atmos. Chem. Phys., 7, 1961-1971, doi:10.5194/acp-71961-2007, 2007.

Petters, M. D., Carrico, C. M., Kreidenweis, S. M., Prenni, A. J., DeMott, P. J., Collett Jr., J. L., and Moosmüller, H.: Cloud condensation nucleation activity of biomass burning aerosol, J. Geophys. Res.-Atmos., 114, D22205, doi:10.1029/2009jd012353, 2009.

Pruppacher, H. R. and Klett, J. D.: Microphysics of clouds and precipitation, Kluwer Academic Publishers, Dordrecht, the Netherlands, 1997.

Roberts, G. C. and Nenes, A.: A Continuous-Flow Streamwise Thermal-Gradient CCN Chamber for Atmospheric Measurements, Aerosol Sci. Tech., 39, 206-221, 2005.

Rose, D., Gunthe, S. S., Mikhailov, E., Frank, G. P., Dusek, U., Andreae, M. O., and Pöschl, U.: Calibration and measurement uncertainties of a continuous-flow cloud condensation nuclei counter (DMT-CCNC): CCN activation of ammonium sulfate and sodium chloride aerosol particles in theory and experiment, Atmos. Chem. Phys., 8, 1153-1179, doi:10.5194/acp-8-11532008, 2008.

Rose, D., Gunthe, S. S., Su, H., Garland, R. M., Yang, H., Berghof, M., Cheng, Y. F., Wehner, B., Achtert, P., Nowak, A., Wiedensohler, A., Takegawa, N., Kondo, Y., Hu, M., Zhang, Y., Andreae, M. O., and Pöschl, U.: Cloud condensation nuclei in polluted air and biomass burning smoke near the mega-city Guangzhou, China - Part 2: Size-resolved aerosol chemical composition, diurnal cycles, and externally mixed weakly $\mathrm{CCN}$-active soot particles, Atmos. Chem. Phys., 11, 2817-2836, doi:10.5194/acp-112817-2011, 2011.

Snider, J. R., Wex, H., Rose, D., Kristensson, A., Stratmann, F., Hennig, T., Henning, S., Kiselev, A., Bilde, M., Burkhart, M., Dusek, U., Frank, G. P., Kiendler-Scharr, A., Mentel, T. F., Petters, M. D., and Pöschl, U.: Intercomparison of cloud condensation nuclei and hygroscopic fraction measurements: Coated soot particles investigated during the LACIS Experiment in November (LExNo), J. Geophys. Res.-Atmos., 115, D11205, doi:10.1029/2009jd012618, 2010.

Su, H., Rose, D., Cheng, Y. F., Gunthe, S. S., Massling, A., Stock, M., Wiedensohler, A., Andreae, M. O., and Pöschl, U.: Hygroscopicity distribution concept for measurement data analysis and modeling of aerosol particle mixing state with regard to hygroscopic growth and CCN activation, Atmos. Chem. Phys., 10, 7489-7503, doi:10.5194/acp-10-7489-2010, 2010.

Wang, Z., Su, H., Wang, X., Ma, N., Wiedensohler, A., Pöschl, U., and Cheng, Y.: Scanning supersaturation condensation particle counter applied as a nano-CCN counter for size-resolved analysis of the hygroscopicity and chemical composition of nanoparticles, Atmos. Meas. Tech., 8, 2161-2172, doi:10.5194/amt-82161-2015, 2015.

Wex, H., Petters, M. D., Carrico, C. M., Hallbauer, E., Massling, A., McMeeking, G. R., Poulain, L., Wu, Z., Kreidenweis, S. M., 
and Stratmann, F.: Towards closing the gap between hygroscopic growth and activation for secondary organic aerosol: Part $1-$ Evidence from measurements, Atmos. Chem. Phys., 9, 3987-3997, doi:10.5194/acp-9-3987-2009, 2009.
Wittbom, C., Eriksson, A. C., Rissler, J., Carlsson, J. E., Roldin, P., Nordin, E. Z., Nilsson, P. T., Swietlicki, E., Pagels, J. H., and Svenningsson, B.: Cloud droplet activity changes of soot aerosol upon smog chamber ageing, Atmos. Chem. Phys., 14, 9831-9854, doi:10.5194/acp-14-9831-2014, 2014. 